\title{
Prediction of 2 Scrip Listed in NSE using Artificial Neural Network
}

\author{
S. L. Pandhripande \\ Department of Chemical Engineering \\ Laxminarayan Institute of Technology, Nagpur \\ University, Nagpur, India
}

\author{
Aasheesh Dixit \\ Department of Chemical Engineering \\ Laxminarayan Institute of Technology, Nagpur \\ University, Nagpur
}

\begin{abstract}
Stock markets in all over the world are becoming the places of activities for trading capital. The performance of stock markets are also viewed as one of the indicators of nation's economy. The importance and magnitude of trading in stock markets can be gauged by the fact that on an average the market cap of NSE and BSE are US\$1.65 trillion and US $\$ 1.7$ trillion respectively. Due to this large amount of money, exchanging hands every day the stock markets have become one of the most complex form of activities difficult to predict. Thus stock market performance prediction have become one of the most challenging tasks to researchers, financial analysts, industrialist and traders. Artificial Neural Network modelling has been successful in diversifying areas, varying from weather predictions, scientific and engineering processes, aerospace, robotics to automobiles. Present work is aimed at forecasting the opening and high prices of the two scrip, Tata Steel ltd. and Snowman logistics ltd., which are listed on NSE and BSE with the help of ANN model.
\end{abstract}

\section{General Terms}

1.1 Stock market, Artificial Neural Network, NSE

\section{Keywords}

Keywords are your own designated keywords which can be used for easy location of the manuscript using any search engines.

\section{INTRODUCTION}

There are many types of trading activities happening in market every day that include trading of stocks and derivatives, indices and commodities etc. The parameters governing performances of these trading activities are many and any. These parameters can be put into two groups, technical and fundamental for individual stock. Technical parameters include opening, closing and high-low prices of the stock, volumes, contracts traded, turnover etc. which are related to the performances of scrip in the market. Fundamental parameters includes inflation, interest rates, balance sheet, quarterly performance, profit and loss margin of the firm, etc.

There are additional parameters that are sentiment driven, which may affect the performance of the scrip. These parameters are perception based and may vary from individual to individual and firm to firm. The list may be long but to name few, the monsoon predictions, political instability, statements of industrialist, RBI policies, world crude/gold prices, dollar exchange rate etc.

The prediction of stock prices involve correlating these several parameters as categorised mentioned in technical, fundamental and sentimental. The conventional mathematical methods have addressed to several modelling situations related to scientific, engineering and financial processes, however forecasting of stocks is still a task to be addressed successfully. Due to emergence of newer computational algorithms and techniques, there is renewed possibility of correlating complex relationships similar those that govern stock prices. Artificial neural network (ANN) is one amongst them.

Artificial neural network Overview: Artificial neural network (ANN) is becoming popular modelling tool for processes where complex multivariable, non-linear relations are involved between input and output parameters. ANN is basically an information processing inter disciplinary theme, having its roots in the working principles of biological neural network system. It is similar to our brain, which receives the information, interprets and gives the output. ANN is composed of a large number of processing elements called as nodes or neurons, which are highly interconnected with each other and work as network to give typical output. Amongst several types of ANN, multilayer perceptron (MLP) is common for modelling multivariable non-linear correlations. It is a feed forward neural network, consisting of multilayer structure. In addition to input and output layers, there are 1-3 hidden layers in between them. The number of nodes in each hidden layer may vary depending upon degree of complexity of correlation to be developed. As a thumb rule, more the number of inputs and output parameters, more will be the nodes in hidden layers. Each node in the preceding layer is connected to all nodes in successive layer by means of constant called as weights. The output from the input layer nodes are fed to the nodes of hidden layer, which in turn feed the output to the next layer nodes. He hidden layer nodes alter the sum of the total input received by them, by applying activation function like sigmoidal or hyperbolic tangent function. The output signals obtained from output layer are compared with target output. The difference between two is referred as error. The reduction of the error is necessary for increasing the effectiveness of network for this purpose, there are training algorithms and one suggested by Rummelhart is popular among researchers.

The novel features of ANN include its ability to interpret from precise data and recognize the patterns; also the speed and accuracy levels are un-parallel. The interesting feature of ANN is no previous knowledge or science behind the process is required and hence they are referred as black box model. Similarly ANN models can take on all linguistic variables or parameters that cannot be measured and conventional modelling methods are thus unsuitable and may fail to give reasons.

ANN modelling has been successful in diversifying areas, varying from weather predictions, scientific and engineering processes, aerospace, robotics to automobiles. 


\section{PRESENT WORK}

Present work is aimed at forecasting the opening and high prices of the two scrip, Tata Steel ltd. and Snowman logistics ltd., which are listed on NSE and BSE.

\subsection{General Introduction to Scrip}

Tata Steel Ldt. is well known company with 108 years of history, net worth of $61,147.99$ crore and market capital of Rs 33,589.49 crore. Its products are exported to several nations. It is listed under large cap blue chip Company and is traded in high volumes. Naturally there are more number of technical, fundamental factors, both national and international, affecting the price of this stock.

Another scrip is Snowman Logistics Ltd, recently listed on September '14 having limited record and relatively less number of parameters affecting its prices. It has Net worth of Rs 221.31 crore. The current market capitalisation stands at Rs $1,454.25$ crore.

\subsection{List of parameters}

The parameters identified by the present work that may be affecting the stock prices of Snowman Logistics and Tata steel are as given in table 1 . There could be many more parameters that are controlling the stock prices, in addition to that listed in the table. However, this is a preliminary investigation in correlating the stock prices of two scrips with principal parameters belonging to the technical data. Additional parameters could be from fundamental data and sentiments driven.

Table 1. Input parameters included in developing ANN models.

\begin{tabular}{|c|c|}
\hline $\begin{array}{c}\text { SNOWMAN LOGISTICS } \\
\text { LTD. }\end{array}$ & TATA STEEL LTD. \\
\hline Previous Close & Previous Close \\
\hline High Price & High Price \\
\hline Low Price & Low Price \\
\hline Last Price & Last Price \\
\hline Close Price & Close Price \\
\hline Average Price & Average Price \\
\hline Total Traded Quantity & Total Traded Quantity \\
\hline Turnover in Lacs & Turnover in Lacs \\
\hline No. of Trades & No. of Trades \\
\hline Deliverable Qty. & Deliverable Qty. \\
\hline \multirow[t]{7}{*}{ \% Dly Qty. to Traded Qty. } & $\begin{array}{l}\text { \% Dly Qty. to Traded } \\
\text { Qty. }\end{array}$ \\
\hline & Open ( index) \\
\hline & High ( index) \\
\hline & Low (index) \\
\hline & Close ( index) \\
\hline & Shares traded \\
\hline & Turnover \\
\hline
\end{tabular}

\subsection{Methodology}

Data are collected for time ' $t$ ' day and prediction is done for ' $\mathrm{t}+1$ ' day.

The methodology followed in the present work is as follows.

1. Two scrip are identified, Tata Steel, and Snowman Logistics.

2. The parameters affecting the stock market price of these scripts are identified and listed as shown in table 1 .

3. The data is collected for Snowman Logistics Ltd. from 26th September to 16th April.

4. The data for Tata Steel Ltd. from 21th April 2014 to 20th April 2015.

5. The data is divided in three parts. The first data set is named as training data set. It is used in developing ANN models. The second data set is termed as test data set, and is not used in developing model. The extent of effectiveness of the developed ANN model is tested using test data set. The third data set is entirely different and is the real measure of efficacy of developed ANN model and termed as validation data set.

6. eLITe-ANN@ is used for developing ANN models that correlate the opening stock market price of the two scrip with the training data set.

7. The topology of ANN is decided by the number of data points, input output parameters and the expected accuracy level. The table gives the details of the topology in the present work used in developing one model for Snowman SN-NN-1 and Tata steel TS-NN-1, TS-NN-2.

8. The trained ANN models SN-NN-1, TS-NN-1, TS $\mathrm{NN}-2$ are then used in forecasting the opening stock prices for training, test and validation data set.

9. Comparison is carried out between actual and forecast values of these scrip for these three data sets. 
Table 2: Details For Input And Output Variable And Type Of Model Used

\begin{tabular}{|c|c|c|c|c|c|c|c|c|}
\hline $\begin{array}{l}\text { ANN } \\
\text { MODEL }\end{array}$ & $\begin{array}{l}\text { NO. OF INPUT } \\
\text { VARIABLES }\end{array}$ & $\begin{array}{l}\text { NO. OF } \\
\text { OUTPUT } \\
\text { VARIABLE }\end{array}$ & $\begin{array}{l}\text { NO } \\
\text { IN } \\
\text { LA }\end{array}$ & $\begin{array}{l}\mathrm{F} \text { NE } \\
\mathrm{RS}\end{array}$ & $\begin{array}{l}\text { ONS } \\
\text { DEN }\end{array}$ & $\begin{array}{l}\text { TYPE OF } \\
\text { ANN } \\
\text { ARCHITE } \\
\text { CTURE }\end{array}$ & $\begin{array}{l}\text { NUMBER OF } \\
\text { ITERATIONS }\end{array}$ & $\begin{array}{l}\text { ROOT } \\
\text { MEAN } \\
\text { SQUARE OF } \\
\text { ERROR } \\
\text { (RMSE) }\end{array}$ \\
\hline & & & $1^{\mathrm{ST}}$ & $2^{\mathrm{ND}}$ & $3^{\mathrm{RD}}$ & & & \\
\hline SM-NN-1 & 11 & 01 & 0 & 10 & 10 & Moderate & 10000 & $\begin{array}{l}\text { Train - .0224 } \\
\text { Test - .0156 }\end{array}$ \\
\hline TS-NN-1 & 17 & 01 & 0 & 10 & 10 & Moderate & 10000 & $\begin{array}{l}\text { Train }-.0135 \\
\text { Test }-.0136\end{array}$ \\
\hline TS-NN-2 & 17 & 01 & 10 & 10 & 10 & Complex & 10000 & $\begin{array}{l}\text { Train }-.0131 \\
\text { Test }-.0147\end{array}$ \\
\hline
\end{tabular}

Table 3: Number Of Data Points Used

\begin{tabular}{|l|l|l|l|}
\hline $\begin{array}{l}\text { ANN } \\
\text { MODEL }\end{array}$ & \multicolumn{4}{|l|}{ NUMBER OF DATA POINTS } \\
\hline & $\begin{array}{l}\text { TRAINING } \\
\text { SET }\end{array}$ & TEST SET & $\begin{array}{l}\text { VALIDATION } \\
\text { SET }\end{array}$ \\
\hline SM-NN-1 & 118 (date) & 10 & 3 \\
\hline TS-NN-1 & 216 (date) & 16 & 13 \\
\hline TS-NN-2 & 215 & 15 & 12 \\
\hline
\end{tabular}

The sample snapshots of eLITe-ANN@ in run mode while developing SM-NN-1 are shown in figures 1

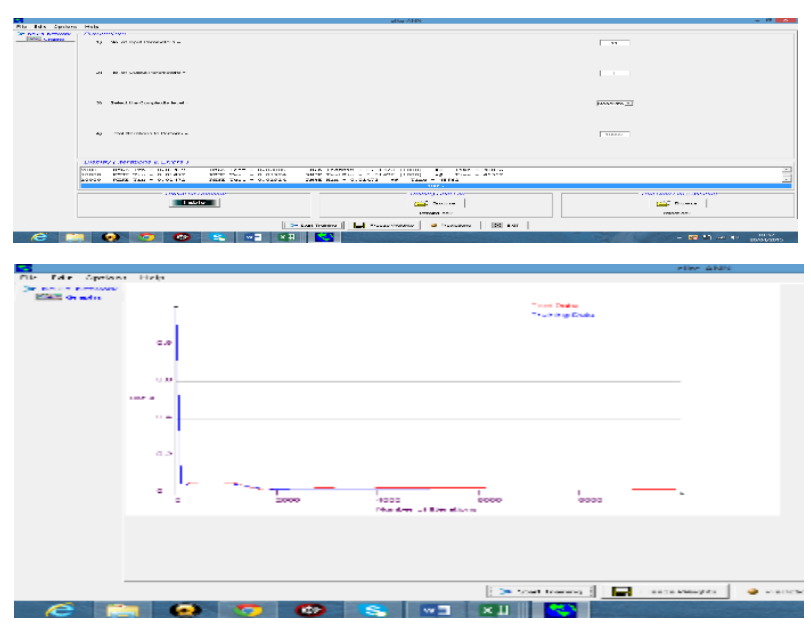

Figure 1. Snapshot of eLITe-ANN in running mode

\subsection{Results and Discussion}

Model SN-NN-1: Figure 2 and 3 show the comparison between the actual and forecast value for the Snowman stock prices for training and test data set respectively.

It can be seen from these graphs, that the accuracy of prediction of opening stock price has been excellent for both training and test data set.

The efficacy of ANN model is based on its ability and accuracy to predict outcome for situations which it has not come across previously. Figure 4 shows the comparison between actual and forecast values for the validation data set.
The predictions are fairly good, indicating the successful development of SN-NN-1 in correlating opening Snowman stock price. To justify this claim further, $\%$ relative error for validation data points calculated and plotted as shown in figure 5. The percentage relative error varies between $-2.5 \%$ to $+3.8 \%$. This is acceptable and can be improved further by employing more data points and input parameters.

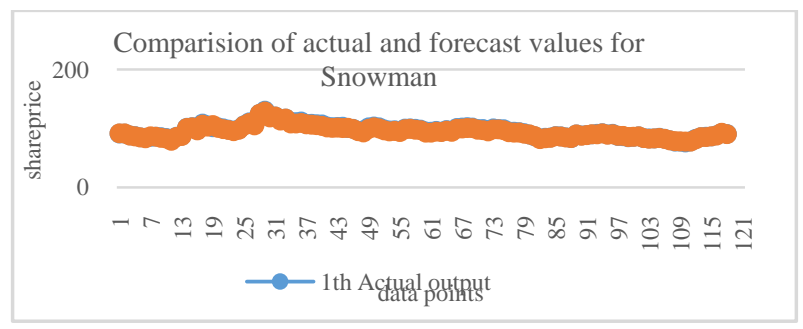

Figure 2. Comparison of actual and forecast values for Snowman

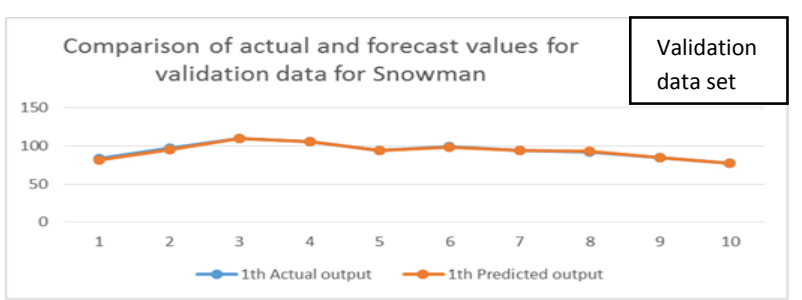

Figure 3. Comparison of actual and forecast values for validation data for Snowman

Comparison of actual and forecast value for validation data for Snowman

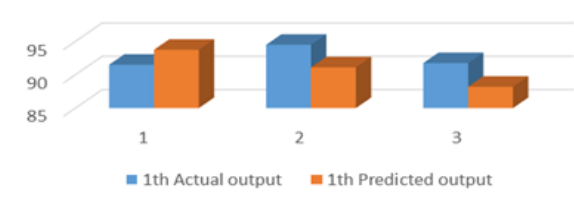

Figure 4. Comparison of actual and forecast value for validation data for Snowman 


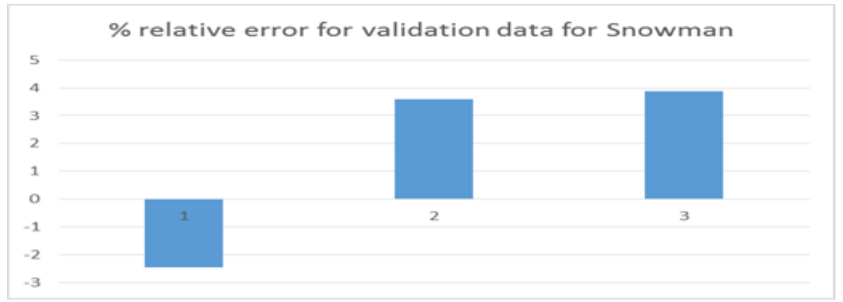

Figure 5. \% relative error for validation data for Snowman

TS-NN-1 and TS-NN-2: Two ANN models are developed for Tata Steel having different topologies. Figure 6 and 7 show the comparison between the actual and forecast value of training and test data set for the opening stock price of TATA steel respectively for model TS-NN-1.

It can be seen from these graphs, that the accuracy of prediction of opening stock price has been excellent for both training and test data set using TS-NN-1. Figure 8 and 9 show the similar comparison using model TS-NN-2. The accuracy of prediction has been excellent for this case also.

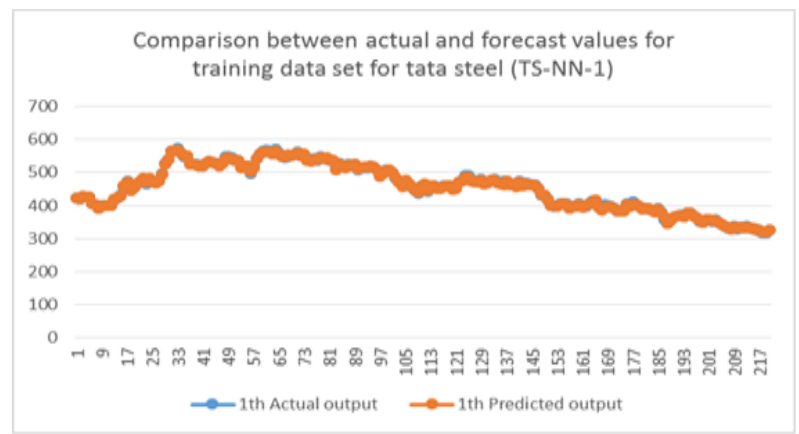

Figure 6: Comparison between actual and forecast values for training data set

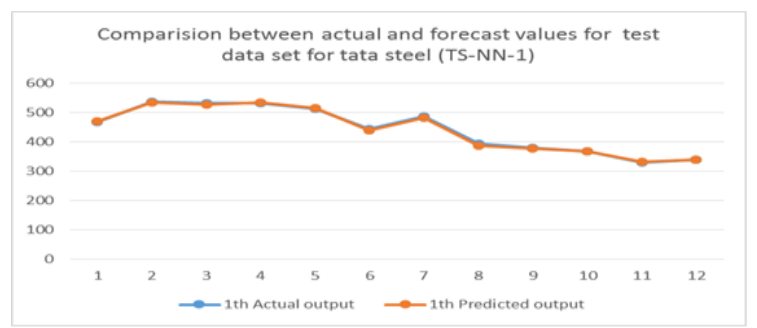

Figure 7: Comparison between actual and forecast values for test data set

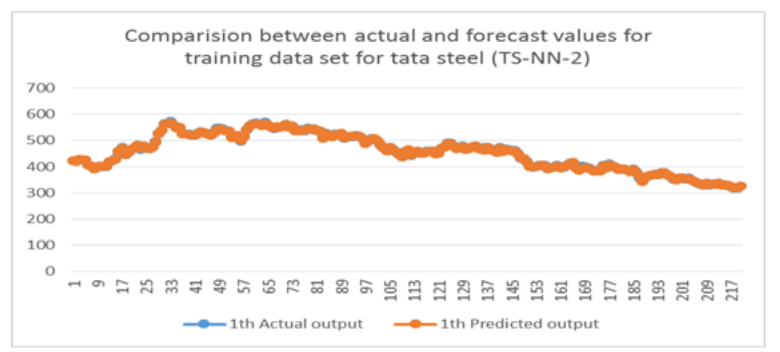

Figure 8: Comparison between actual and forecast values for training data set

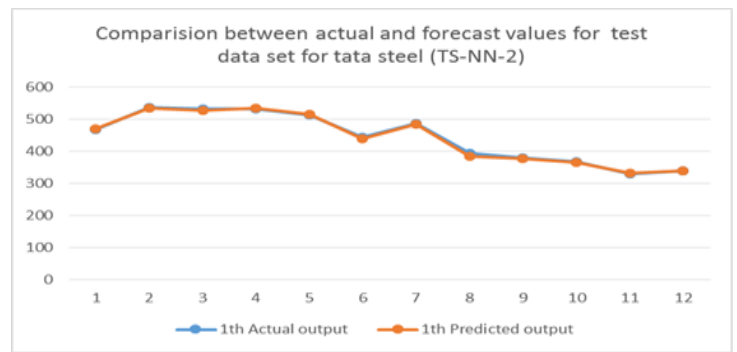

Figure 9: Comparison between actual and forecast values for test data set

The efficacy of ANN models developed is further checked and Figure 10 and 11 show the comparison between actual and forecast value for the validation data set for TS-NN-1 and TS-NN-2 respectively. The predictions are very close to the actual values indicating the successful development of TSNN-1 and TS-NN-2 in correlating opening Tata steel stock price.

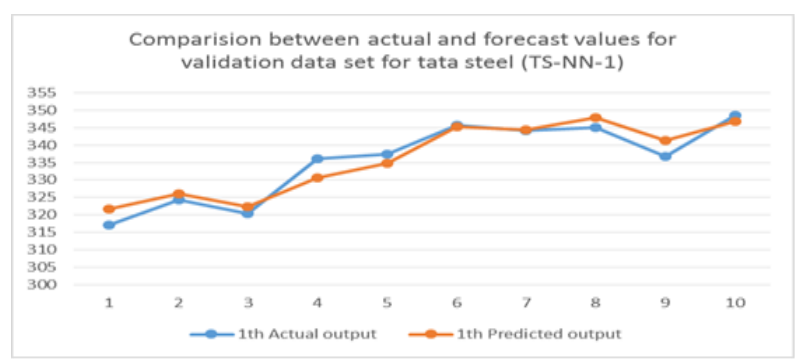

Figure 10: Comparison between actual and forecast values for validation data set

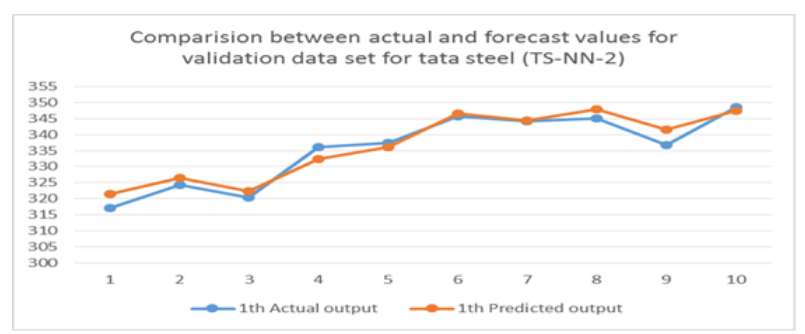

Figure 11: Comparison between actual and forecast values for validation data set

The present work is also aimed at the effect of topology on efficacy of the models developed. Two ANN models TS-NN1 and TS-NN-2 are developed and the preceding sections have presented the accuracy of predictions in estimation of opening Tata steel stock price. Both the models have excellent prediction accuracy. However figure 12 shows the comparison between the $\%$ relative error for validation data set for TS$\mathrm{NN}-1$ and TS-NN-2. The range for TS-NN-1 is between $0.08 \%$ to $1.6 \%$, whereas for TS-NN-2 it is $.029 \%$ to $1.4 \%$.

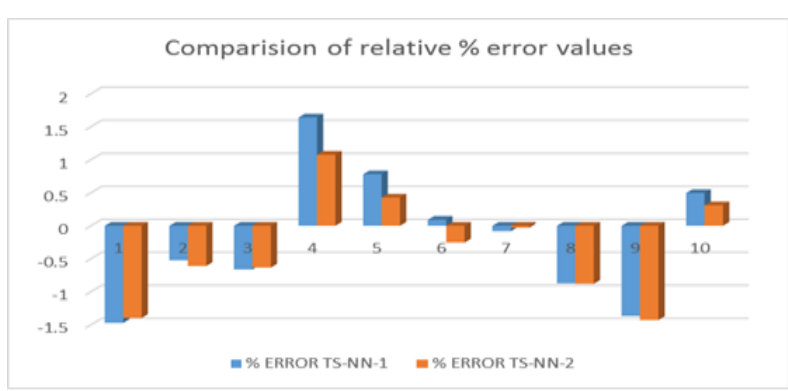

Figure 12: Comparison of relative \% error values 


\section{CONCLUSIONS}

The stock price prediction is topic of interest amongst one and all. As there are number of parameters affecting the stock price and the exact science behind this phenomena is not known, the task becomes complex and conventional methods fail. Artificial neural network is viewed as alternate modelling tool for such a situations where the data is either incomplete or the science behind the process is not known.

The present work addressed to the forecast of opening stock price of two scripts Snowman Logistics LTD. and Tata steel ltd using ANN. Three ANN models SN-NN-1, TS-NN-1 and TS-NN-2 are developed with different topologies and with 11 input parameter for Snowman and 20 input parameter for Tata Steel.

Forecast of prices obtained using these models for three types of data sets namely training, test and validation are compared for study of the effectiveness. Based on these comparisons its can be said that the present work has successfully meet with the objective. This can be substantiated by the fact that $\%$ relative error is between $-2.5 \%$ to $+3.8 \%$ for $\mathrm{SN}, 0.08 \%$ to $1.6 \%$ for TS 1,2 . This is highly acceptable and satisfactory.

The work is demonstrative and given the nature and volatility of the topic it is felt necessary that more number of data points, input parameters and topologies of ANN need to be undertaken for future work, so as to make it more confirmatory.

\section{ACKNOWLEDGMENTS}

Authors are thankful to the Director LIT, and NSE site for data.

\section{REFERENCES}

[1] eLITe-ANN $^{\odot}$

[2] Stock Price Prediction Using Artificial Neural Network, Mayankkumar B Patel 1, Sunil R Yalamalle 2, Journal of Emerging Trends in Computing and Information Sciences

[3] Prediction of the Bombay Stock Exchange (BSE) Market Returns Using Artificial Neural Network and Genetic Algorithm, Yusuf Perwej1, Asif Perwej2, Journal of Intelligent Learning Systems and Applications, 2012, 4, 108-119

[4] Stock Market Prediction Using Artificial Neural Networks, Bhagwant Chauhan, Umesh Bidave, Ajit Gangathade, Sachin Kale, (IJCSIT) International Journal of Computer Science and Information Technologies, Vol. 5 (1) , 2014, 904-907

[5] FORECASTING OF INDIAN STOCK MARKET INDEX USING ARTIFICIAL NEURAL NETWORK, Manna Majumder, MD Anwar Hussian,

[6] Stock Prediction Using Artificial Neural Networks, A. Victor Devadoss, T. Antony Alphonnse Ligori, International Journal of Data Mining Techniques and Applications, Vol:02, December 2013, Pages: 283-291

[7] Application of Artificial Neural Network for stock market predictions: A review of literature, Dase R.K. and Pawar D.D, International Journal of Machine Intelligence, ISSN: 0975-2927, Volume 2, Issue 2, 2010, pp-14-17 